\title{
Pulmonary Epithelial-Myoepithelial Tumor of Unproven Malignant Potential: Report of a Case and Review of the Literature
}

Giuseppe Pelosi, M.D., M.I.A.C., Filippo Fraggetta, M.D., Fausto Maffini, M.D., Piergiorgio Solli, M.D., Alessandra Cavallon, Giuseppe Viale, M.D., F.R.C.Path.

Department of Pathology and Laboratory Medicine (GP, FF, FM, AC, GV), European Institute of Oncology and University of Milan School of Medicine; and Department of Thoracic Surgery (PS), European Institute of Oncology, Milan, Italy

Epithelial-myoepithelial tumors of the lung are rare neoplasms whose biological behavior and clinical course still remain to be defined. A case of epithelialmyoepithelial tumor of the lung arising from bronchial mucosa-submucosa and occurring as a polypoid lesion of the upper left bronchus in a 47-year-old man is reported. The tumor did not infiltrate the cartilaginous wall of the bronchus and showed a biphasic histological appearance with a double layering of epithelial and myoepithelial cells. Myoepithelial spindle cells with eosinophilic cytoplasm were also observed. Mitotic figures were very rare and necrosis absent. Immunohistochemical study for epithelial and muscular markers confirmed the presence of a double-cell component in the tumor, namely epithelial and myoepithelial. The patient is alive and well, with no evidence of recurrent or metastatic disease 6 months after surgery. On the basis of the present case and the six previously reported cases, we suggest using the noncommittal term pulmonary epithelial-myoepithelial tumor of unproven malignant potential (PEMTUMP) for this type of neoplasm. In addition, we first introduce p63 as a novel marker for highlighting the myoepithelial cells of the respiratory tract and speculate on the role of these cells in the development of this unusual tumor.

KEY WORDS: Epithelial, Immunohistochemistry, Malignant potential, Myoepithelial, p27, p63, Tumor.

Mod Pathol 2001;14(5):521-526

Copyright (C) 2001 by The United States and Canadian Academy of Pathology, Inc.

VOL. 14, NO. 5, P. 521, 2001 Printed in the U.S.A.

Date of acceptance: January 11, 2001.

Address reprint requests to: Giuseppe Pelosi, M.D., M.I.A.C., Department of Pathology and Laboratory Medicine, European Institute of Oncology, Via G. Ripamonti 435, 20141 Milano, Italy; e-mail: giuseppe.pelosi@ieo.it; fax: +39-02-57489417.
Submucosal tracheobronchial glands are considered the pulmonary counterpart of the minor salivary glands of the head and neck, and may harbor most of the tumors arising in salivary glands. Overall, salivary-type tumors of the lung are rather uncommon, despite the widespread distribution of mucosal-submucosal glands in the normal tracheobronchial tree $(1,2)$. These tumors most commonly recapitulate the morphological features of the neoplasms of minor salivary glands, the most frequent being mucoepidermoid and adenoid cystic carcinomas (3). Interestingly, benign tumors such as pleomorphic adenoma occur in the lung as uncommonly as in the minor salivary glands. Because the tumors originating from mucosal-submucosal glands develop mostly in the proximal bronchial tree, they present usually as polypoid endobronchial lesions (3-5), though an intraparenchymal growth without any connection with the bronchi has been occasionally reported (6).

Salivary gland tumors composed exclusively of a mixture of epithelial and myoepithelial cells are designated epithelial-myoepithelial carcinomas and are considered of low-grade malignancy (7). Tumors of the lung with a similar admixture of epithelial and myoepithelial cells are very uncommon, and, to our knowledge, only six welldocumented cases have been reported in the English literature $(4,8-12$; Table 1$)$. None of these tumors actually pursued a malignant clinical course, though the follow-up time has been too short for conclusively ascertaining their clinical behavior.

Here we report on an additional example of pulmonary epithelial-myoepithelial tumor, running a benign clinical course after 6 months of follow-up. Although this tumor did not show any histological and clinical feature of malignancy, we suggest using the noncommittal designation of PEMTUMP for 
TABLE 1. Epithelial-Myoepithelial Tumors of the Tracheobronchial Tree: Data of the Literature

\begin{tabular}{|c|c|c|c|c|c|}
\hline Author Group & Age/Sex & $\begin{array}{c}\text { Smoking } \\
\text { Habit }\end{array}$ & $\begin{array}{l}\text { Size } \\
(\mathrm{cm})\end{array}$ & Localization & Follow-up \\
\hline Horinouchi et al., 1993 & $57 / \mathrm{F}$ & NA & 2.2 & trachea & NA \\
\hline Nistal et al., 1994 & $55 / \mathrm{F}$ & Yes & 2 & RULB & AW after 2 years \\
\hline Tsuji et al., 1995 & $66 / \mathrm{M}$ & Yes & 16 & $\begin{array}{l}\text { Parenchymal/endobronchial } \\
\text { right intermediate } \\
\text { bronchus }\end{array}$ & $\begin{array}{l}\text { Well after } 36 \text { months; } \\
\text { now dead of } \\
\text { unrelated disease }\end{array}$ \\
\hline Wilson et al., 1997 & $55 / \mathrm{F}$ & No & 3.9 & LBSB & AW after 7 months \\
\hline Shanks et al., 1998 & $67 / \mathrm{M}$ & Yes & 1.3 & LLLB & Lost to follow-up \\
\hline Ryska et al., 1998 & $47 / \mathrm{F}$ & NA & NA & RULB & AW after 13 months \\
\hline Present case & $47 / \mathrm{M}$ & No & 1.5 & LULB & AW after 6 months \\
\hline
\end{tabular}

NA, not available; AW, alive and well; RULB, right upper bronchial bronchus; LBSB, lateral basal segment bronchus; LLLB, left lower lobar bronchus; LULB, left upper lobar bronchus.

this neoplasm because of its unpredictable clinical behavior.

\section{CASE REPORT}

A 47-year-old man with no history of neoplasia, smoking habit, or pulmonary infectious disease, underwent standard chest X-rays and fiberoptic bronchoscopy because of hyperpirexya, cough, hemophtysis, and chest pain for the past few weeks. Laboratory findings were unremarkable. Radiography disclosed an opacity in the left lung, which at bronchoscopy corresponded to a whitish to gray, polypoid lesion partially occluding the lumen of the left upper lobar bronchus. Total body computedtomography scan showed a $2-\mathrm{cm}$ nodule at the hilum of the left upper lobe, with no associated enlargement of hilar or mediastinal lymph nodes (Fig 1A). Moreover, two additional nodules were disclosed in the IVth and VIth segments of the liver, which were histologically proven to be focal nodular hyperplasia of the liver. Therefore, a pulmonary upper sleeve lobectomy was performed with mediastinal lymph node dissection. Postoperative course was uneventful, and the patient was discharged on the seventh postoperative day.

\section{METHODS}

Formalin-fixed and paraffin-embedded sections were stained with hematoxylin-eosin and periodic acid-Schiff with and without diastase digestion. Additional sections were immunostained with the panel of antibodies listed in Table 2. A commercially available detection kit (Dako EnVision PlusHRP, DAKO, Glostrup, Denmark) was used according to the manufacturer's instructions. Double immunostains for smooth muscle actin and p63 protein were carried out to highlight the differential distribution of p63 in epithelial and myoepithelial cells of the tumor and the normal respiratory tract. Briefly, the first immunostaining was carried out by means of a commercially available detection kit (Universal Large Volume LSAB Kit HRP, DAKO) us- ing the p63 monoclonal antibody as a primary antibody reagent and 3-3'-diaminobenzidine (Sigma Chemical Co, St Louis, MO) as a chromogen substrate to obtain a brown end-product. Subsequently, a second immunostaining for smooth muscle actin was added using the EnVision Plusalkaline phosphatase kit (DAKO), and New Fuchsin was used (Merck, Darmstadt, Germany) as a second substrate to yield a red end-product. Slides were lightly counterstained with $1 \%$ Harris' hematoxylin.

\section{RESULTS}

Grossly, the neoplasm measured $1.5 \mathrm{~cm}$ in maximum diameter and protruded into the bronchial lumen without infiltrating the cartilaginous wall of the bronchus (Fig. 1B,C). On cut surface, it was pink, with no evidence of necrosis or hemorrhage. Pulmonary parenchyma and thoracic lymph nodes were unremarkable.

Histologically, the tumor was confined to the bronchial mucosa and submucosa with pushing growth margins, without invasion of the cartilage and the smooth muscle layer. It showed a biphasic architecture, composed of glands and spindle cells (Fig. 2A) The glands were lined by a double layer of cells, the inner consisting of epithelial cells, the outer of myoepithelial cells. The epithelial cells were flattened or cuboidal, with pink cytoplasm and basal nuclei. A colloidlike, periodic acid-Schiffpositive and diastase-resistant material filled the glandular lumina. The myoepithelial cells were round or polygonal and exhibited either a clear or eosinophilic cytoplasm (Fig. 2B). These glandular structures blended into areas composed predominantly of spindle cells with eosinophilic cytoplasm. Mitotic figures were very rare and not restricted to either cellular components. In some areas, residual and sometimes hyperplastic mucous glands were encountered. No necrosis, vascular or neural invasion, or cell atypia were observed in either the epithelial and myoepithelial components.

The myoepithelial cells were consistently and strongly immunoreactive for S-100 protein and ac- 

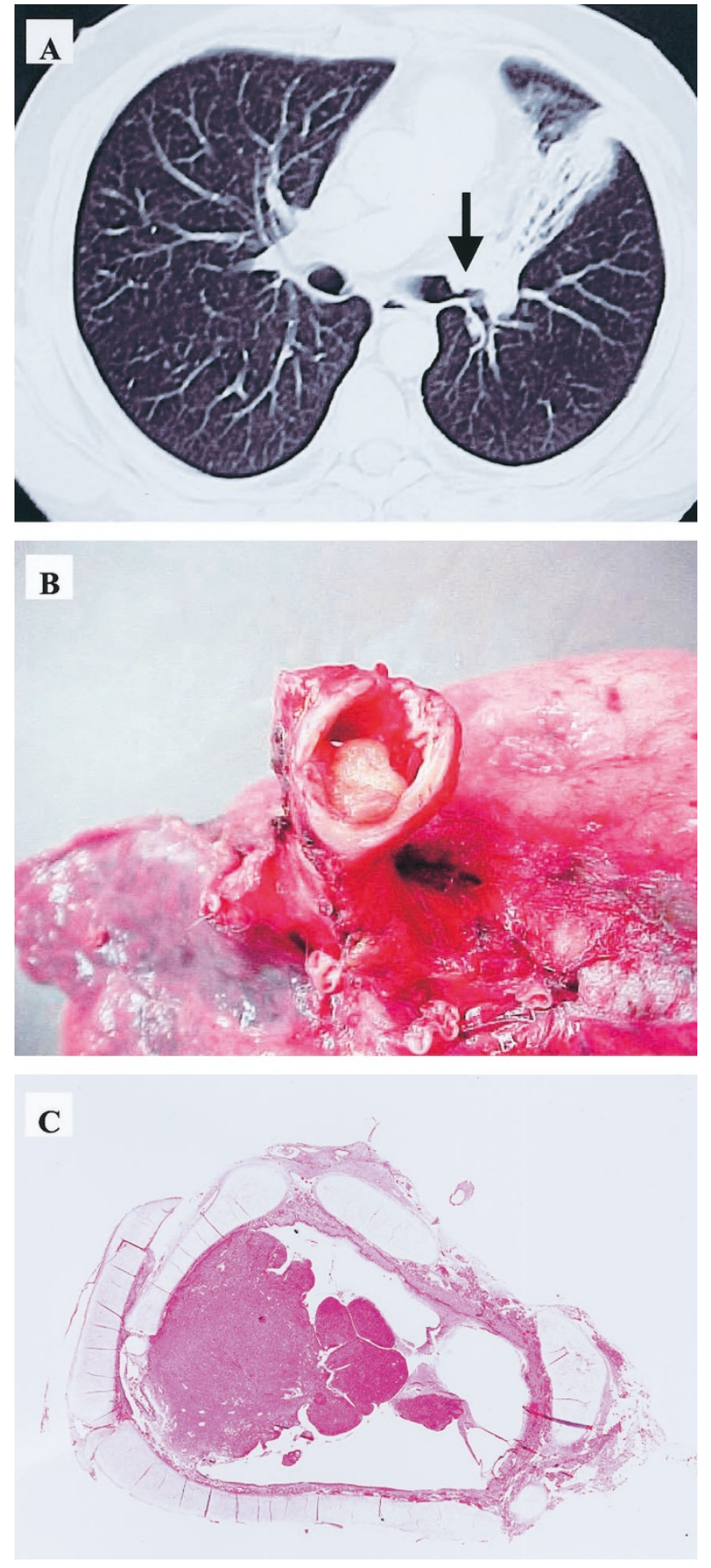

FIGURE 1. Gross appearance of PEMTUMP. A, Computed tomography scan showing an endobronchial growth in the hilum of the left upper lobe (arrow) without lymph node enlargement. B, The tumor occludes partially the lumen of lobar bronchus. C, Whole-mount section showing a polypoid growth protruding into the bronchial lumen without invasion of the cartilaginous wall and smooth muscle layer of the bronchus.

tin (smooth muscle actin and HHF-35; Fig. 2C). p63 gene product was focalized in the nuclei of $45 \%$ of these cells, but very rarely in the neoplastic epithelial cells (Fig. 2H). p63 immunoreactivity was also detected in basal cells of the bronchial epithelium and in myoepithelial cells of the normal bronchial mucous glands (Fig. 2G). Intense reactivity for cytokeratins was observed in the epithelial cells, whereas it was weaker in the myoepithelial cells (Fig. 2D). S-100 protein was predominantly immunolocalized in the myoepithelial cells and, occasionally, in the epithelial cells. Immunoreactivity for p27/Kip-1 protein was more prevalent in epithelial rather than myoepithelial cells $(22.5 \%$ versus 10.1\%) (Fig. 2E), with three different patterns of staining, namely, nuclear (3\% versus $1.6 \%$ ), cytoplasmic $(8.8 \%$ versus $6.9 \%)$, or combined $(10.7 \%$ versus $1.6 \% ; P=.002$ ). The proliferating fraction assessed by Ki-67 antigen immunoreactivity was $1.5 \%$ among the epithelial cells and $12 \%$ in the myoepithelial cell component (Fig. 2F). An inverse relationship between p27 protein expression and proliferative activity was assessed in both epithelial and myoepithelial cells $(P<0.001)$. There was no immunoreactivity for TTF-1 and p53 protein.

A final diagnosis of epithelial-myoepithelial tumor of the lung was rendered. The patient is alive, with no sign of recurrence, 6 months after surgery.

\section{DISCUSSION}

The final diagnosis of epithelial-myoepithelial tumor of the lung was based on the identification of a dual population of tumor cells with morphological and immunohistochemical characteristics of epithelial and myoepithelial cells.

The differential diagnosis of this neoplasms is quite broad and depends on the relative predominance of the myoepithelial cells (especially of those with clear appearance), or of the biphasic pattern. Pleomorphic adenoma, mucous gland adenoma, adenoid cystic carcinoma, sugar tumor, and metastatic tumors are the most common neoplasms to be differentiated from the PEMTUMP.

Pleomorphic adenoma is exceedingly rare in the lung and is characterized by a myxochondroid matrix or chondroid stromal nodules in addition to a mixture of ductal and myoepithelial cells $(2,3)$. Mucous gland adenoma is rare but should be taken into account for the occurrence of cystically dilated glands filled by colloid-like, eosinophilic material (3). However, the glands are generally lined by columnar to flattened, mucus-secreting cells lacking a myoepithelial cell layer. Adenoid cystic carcinoma is one of the most common salivary gland-type tumors of the lung. It typically shows an extensively invasive growth pattern and has a cribriform pattern and remarkable perineural invasion $(2,3)$. Sugar tumor often presents as an asymptomatic coin lesion in the periphery of the lung, without relation with visible bronchi, and does not display tubular structures or a dual population of neoplastic cells. Furthermore, the majority of sugar tumors 
TABLE 2. Reagents Used in the Immunohistochemical Characterization

\begin{tabular}{lccll}
\hline \multicolumn{1}{c}{ Antibody } & $\mathrm{m} / \mathrm{p}$ & Clone & Dilution & Source \\
\hline Cytokeratin pool & $\mathrm{m}$ & AE1-AE3 & $1: 50$ & Novocastra \\
S-100 protein & $\mathrm{p}$ & - & $1: 1600$ & DAKO \\
Smooth muscle actin & $\mathrm{m}$ & $1 \mathrm{~A} 4$ & $1: 200$ & DAKO \\
Muscle actin & $\mathrm{m}$ & HHF35 & $1: 50$ & DAKO \\
p63 protein & $\mathrm{m}$ & $\mathrm{mA4}$ & $1: 500$ & Courtesy of Jon Askaa (DAKO) \\
p53 protein & $\mathrm{m}$ & $\mathrm{DO}$ & $1: 1000$ & DAKO \\
p27/Kip-1 protein & $\mathrm{m}$ & $\mathrm{m}$ & $1: 600$ & Transduction \\
TTF-1 & $\mathrm{m}$ & $\mathrm{m}$ & $1: 50$ & NeoMarkers \\
Ki-67 antigen & $\mathrm{m}$ & MIB-1 & Immunotech & \\
\hline
\end{tabular}

TTF-1, thyroid transcription factor- $1 ; \mathrm{m} / \mathrm{p}$, monoclonal/polyclonal.

${ }^{a}$ Novocastra Laboratories, Newcastle upon Tyne, UK; DAKO, Glostrup, Denmark; Transduction Laboratories, Lexington, KY, NeoMarkers, Union City, CA; and Immunotech, Marseille, France.

are immunoreactive for the antimelanocytic marker HMB-45, and not for cytokeratins $(2,3)$. Finally, the clinical history and the accurate histological features aid in differentiating PEMTUMP from metastatic tumors of either salivary or other (i.e., clear cell renal carcinoma) origin or from pulmonary adenocarcinomas with prominent endobronchial pattern of growth $(2,3)$.

To the best of our knowledge only six cases of epithelial-myoepithelial tumor of the lower respiratory tract have been reported previously (Table 1). They usually occur in middle aged patients with a slight female predilection ( $\mathrm{F}: \mathrm{M}=2: 1$ ), and present as a polypoid endobronchial lesion. Tumor size ranges from $1.3 \mathrm{~cm}$ to $16 \mathrm{~cm}$, with a median value of $2.1 \mathrm{~cm}$.

Pulmonary neoplasms composed mainly or exclusively of epithelial and myoepithelial cells have been designated in the past under a variety of descriptive terms, including adenomyoepithelioma (10), epithelial-myoepithelial tumor $(8,9)$, and epithelial myoepithelial carcinoma $(4,11,12)$. However, their clinical behavior remains to be ascertained, mainly because of the lack of an adequate follow-up time.

Epithelial-myoepithelial tumors of the salivary glands behave as low-grade malignant neoplasms, with a long interval between the original diagnosis and local recurrence (mean time: 5 y) or distant metastases (mean time: 15 yr) (7, 13-16). Accordingly, some authors consider this the most likely clinical behavior of the corresponding tumors of the lung (4, 11). None of the pulmonary neoplasms, however, showed local recurrences or metastases, although the short follow-up time (from a few to 49 months) does not allow a more aggressive behavior to be excluded over time. Because of the lack of cytological atypia, remarkable mitotic activity, necrosis, or invasiveness, some authors maintain the noncommittal designation of epithelial-myoepithelial tumor for these pulmonary neoplasms $(8,9)$.

Recently, Seifert (17) paralleled epithelial-myoepithelial tumors of the salivary glands and adenomyoepitheliomas of the breast, suggesting that a dif- ferent clinical course of the latter could be justified by the size of the tumors. Pulmonary epithelialmyoepithelial tumors are usually of small size when detected, for the early symptomatology due to their endobronchial localization. This could in part explain their indolent course. On the other hand, reported markers of malignancy in epithelial-myoepithelial tumors of salivary glands, such as brisk mitotic activity, frankly invasive growth, and neural and vascular invasion were not detected in our case.

Taking into account all these considerations, we suggest designating these peculiar biphasic tumors as PEMTUMP. This is not to exclude $a$ priori a biological parallel with the corresponding tumors of the salivary glands but to emphasize the stillundetermined clinical behavior of these pulmonary neoplasms.

A peculiar feature of the present case was the extensive component of myoepithelial cells of both polygonal and spindle shape. Myoepithelial cells may be sometimes difficult to recognize on purely morphological grounds, and their histological variability may hamper their identification. Immunohistochemically, myoepithelial cells usually express S100 protein, smooth muscle myosin, calponin, actin, and high-molecular weight cytokeratins (18). However, immunoreactivity for S100 protein may be lacking, and clear-cell myoepitheliomas unreactive for actin are also on record, possibly because of their degree of differentiation (19).

Here we document that $45 \%$ of myoepithelial cells, as well as basal cells of bronchial epithelium and myoepithelial cells of the normal bronchial mucous glands, but virtually no luminal epithelial cells, were strongly immunoreactive for the p63 gene product. p63 protein, a newly recognized member of the p53 gene family with function yet largely unknown, is expressed in proliferating basal cells of the epidermis, uterine cervix, urothelium, and prostate (20). In normal lung, p63 is restricted to basal cells of the respiratory epithelium and to peripheral, flattened cells of bronchial mucous glands resembling myoepithelial cells. Likewise, in breast tissue, it is exclusively confined to myoepi- 

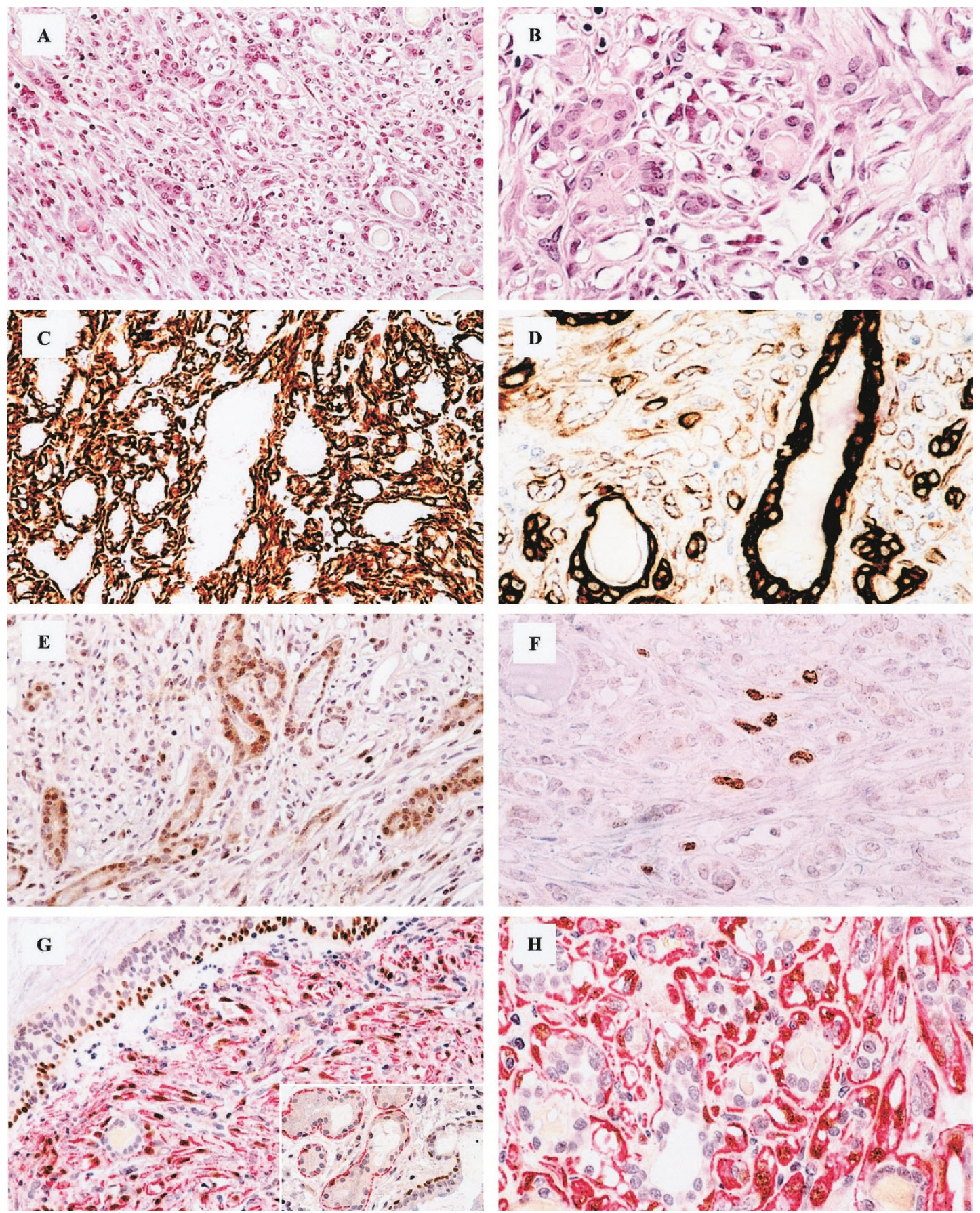

FIGURE 2. Histologic features of PEMTUMP. A, The tumor shows biphasic architecture, with glands filled by colloid-like material and spindle cells. The glands consist of an inner layer of epithelial cells and an outer layer of myoepithelial cells, sometimes with clear cytoplasm (B). Myoepithelial cells are highlighted by smooth muscle actin immunoreactivity $(\mathbf{C})$, whereas intense staining for cytokeratins occurs in epithelial cells and more weakly in myoepithelial cells (D). Immunoreactivity for p27/Kip-1 is prevalent in epithelial cells, showing both nuclear and cytoplasmic localization (E). Overall, the proliferative activity assessed by Ki-67 index is low, but in the myoepithelial cell compartment, it is consistently higher, showing an inverse relationship with p27/Kip-1 expression (F). p63 protein is distributed in basal cells of respiratory epithelium and myoepithelial cells of normal bronchial glands (inset, G), as well as in myoepithelial but not epithelial cells of the tumor (H). (Staining was as follows. A, B: hematoxylin and eosin; G, H: double immunostains for smooth muscle actin [red, EnVision Plus-alkaline phosphatase kit method] and p63 protein [brown, Universal Large Volume LSAB-HRP kit method].)

thelial cells (Doglioni et al., personal communication). This suggests that p63 protein could be added to the list of other immunohistochemical markers of myoepithelial cells, as S-100 protein, actin, smooth muscle myosin heavy chain, calponin, and high molecular weight cytokeratins (18).
Contrary to the neoplastic epithelial cells of the glandular structures, showing nuclear and cytoplasmic immunoreactivity for p27/Kip-1, the tumor myoepithelial cells exhibited predominantly a cytoplasmic staining. Cytoplasmic localization of p27/ Kip-1 protein has been demonstrated mostly in 
early dysplastic lesions and well differentiated carcinomas, rather than in invasive and poorly differentiated tumors $(21,22)$. This suggests that an aberrant subcellular localization of p27/Kip-1 in the neoplastic myoepithelial cells could abrogate its growth-inhibiting function and contribute to tumorigenesis via the unrestricted proliferation of the myoepithelial component. In fact, proliferating cells were found preferentially among the myoepithelial cells, which could thus represent a stem or reserve compartment of this tumor, as also recently demonstrated in mammary adenomyoepitheliomas (23). Furthermore, a significant inverse relationship was noted between the expression of cell cycle inhibitor p27/Kip-1 protein and the proliferative activity in both cell types.

\section{REFERENCES}

1. Moran CA. Primary salivary gland-type tumors of the lung. Semin Diagn Pathol 1995;12:106-122.

2. Corrin B. Pathology of the lungs. 1st ed. London: Churchill Livingstone; 2000.

3. Travis WD, Colby TV, Corrin B, Shimosato Y, Brambilla E. Hystological typing of lung and pleural tumours. New York: Springer Verlag; 1999.

4. Wilson RW, Moran CA. Epithelial-myoepithelial carcinoma of the lung: immunohistochemical and ultrastructural observations and review of the literature. Hum Pathol 1997;28: 631-5.

5. Higashiyama M, Kodama K, Yokouchi H, Takami K, Kabuto T, Tsuji N, et al. Myoepithelioma of the lung: report of two cases and review of the literature. Lung Cancer 1998;20:4756.

6. Strickler JG, Hegstrom J, Thomas MJ, Yousem SA. Myoepithelioma of the lung. Arch Pathol Lab Med 1987;111:1082-5.

7. Cho KJ, el-Naggar AK, Ordonez NG, Luna MA, Austin J, Batsakis JG. Epithelial-myoepithelial carcinoma of salivary glands. A clinicopathologic, DNA flow cytometric, and immunohistochemical study of Ki-67 and HER-2/neu oncogene. Am J Clin Pathol 1995;103:432-7.

8. Horinouchi H, Ishihara T, Kawamura M, Kato R, Kikuchi K, Kobayashi K, et al. Epithelial myoepithelial tumour of the tracheal gland. J Clin Pathol 1993;46:185-7.
9. Nistal M, Garcia-Viera M, Martinez-Garcia C, Paniagua R. Epithelial-myoepithelial tumor of the bronchus. Am J Surg Pathol 1994;18:421-5.

10. Tsuji N, Tateishi R, Ishiguro S, Terao T, Higashiyama M. Adenomyoepithelioma of the lung. Am J Surg Pathol 1995; 19:956-62.

11. Ryska A, Kerekes Z, Hovorkova E, Barton P. Epithelialmyoepithelial carcinoma of the bronchus. Pathol Res Pract 1998;194:431-5.

12. Shanks JH, Hasleton PS, Curry A, Rahman A. Bronchial epithelial-myoepithelial carcinoma. Histopathology 1998;33: 90-1.

13. Kasper HU, Mellin W, Kriegsmann J, Cheremet E, Lippert H, Roessner A. Epithelial-myoepithelial carcinoma of the salivary gland-a low grade malignant neoplasm? Report of two cases and review of the literature. Pathol Res Pract 1999;195: 189-92.

14. Kasper HU, Roessner A. Epithelial-myoepithelial carcinoma [Letter]. Am J Surg Pathol 2000;24:308.

15. Tsuneyama K, Hoso M, Kono N, Kitagawa M, Masuda S, Matsuki N, et al. An unusual case of epithelial-myoepithelial carcinoma of the liver. Am J Surg Pathol 1999;23:349-53.

16. Tsuneyama K, Nakanuma Y. Epithelial-myoepithelial carcinoma [Authors' reply]. Am J Surg Pathol 2000;24:308.

17. Seifert G. Are adenomyoepithelioma of the breast and epithelial-myoepithelial carcinoma of the salivary glands identical tumours? Virchows Arch 1998;433:285-8.

18. Savera AT, Sloman A, Huvos AG, Klimstra DS. Myoepithelial carcinoma of salivary glands: a clinicopathologic study of 25 patients. Am J Surg Pathol 2000;24:761-74.

19. Alos L, Cardesa A, Bombi JA, Mallofre C, Cuchi A, Traserra J. Myoepithelial tumors of salivary glands: a clinicopathologic, immunohistochemical, ultrastructural, and flow-cytometric study. Semin Diagn Pathol 1996;13:138-47.

20. Yang A, Kaghad M, Wang Y, Gillett E, Fleming MD, Dotsch V, et al. p63, a p53 homolog at 3q27-29, encodes multiple products with transactivating, death-inducing, and dominant-negative activities. Mol Cell 1998;2:305-16.

21. Sgambato A, Ratto C, Faraglia B, Merico M, Ardito R, Schinzari G, et al. Reduced expression and altered subcellular localization of the cyclin-dependent kinase inhibitor p27/ Kip1 in human colon cancer. Mol Carcinog 1999;26:172-9.

22. Singh SP, Lipman J, Goldman H, Ellis FH, Aizenman L, Cangi MG, et al. Loss or altered subcellular localization of p27 in Barrett's associated adenocarcinoma. Cancer Res 1998;58: $1730-5$.

23. Koyama M, Kurotaki H, Yagihashi N, Aizawa S, Sugai M, Kamata $\mathrm{Y}$, et al. Immunohistochemical assessment of proliferative activity in mammary adenomyoepithelioma. Histopathology 1997;31:134-9. 